\title{
MULHERES CHEFES DE FAMÍLIA E A PERSPECTIVA DE GÊNERO: trajetória de um tema e a crítica sobre a feminização da pobreza ${ }^{1}$
}

\author{
Márcia dos Santos Macedo*
}

\begin{abstract}
Este ensaio apresenta um breve resgate da trajetória dos estudos sobre mulheres chefes de família e realiza uma reflexão crítica sobre a relação direta que vem sendo estabelecida entre o crescimento do fenômeno da chefia familiar feminina e o controvertido debate em torno da chamada feminização da pobreza. Busca apontar para a necessidade do questionamento de uma homogeneidade artificial construída em torno das mulheres em situação de chefia de seus núcleos doméstico-familiares, apresentada pela maioria dos estudos, e que insiste em reforçar um perfil uniforme dessas mulheres - vistas, predominantemente, como as mais pobres entre os pobres -, e sinaliza, por fim, para as possibilidades abertas pelos estudos de gênero, particularmente daqueles que se filiam a uma epistemologia feminista e relacional, para um novo olhar sobre esse objeto polissêmico e multifacetado.

PALAVRAS-CHAVE: mulheres chefes de família, feminização da pobreza, relações de gênero.
\end{abstract}

\section{INTRODUÇÃO}

Neste ensaio, procuro, simultaneamente, apresentar uma breve trajetória dos estudos sobre mulheres chefes de família e uma reflexão crítica sobre a relação direta que vem sendo estabelecida entre esse fenômeno e o controvertido debate da chamada feminização da pobreza. Nesse sentido, busco apontar para a necessidade do questionamento de uma homogeneidade artificial construída em torno das mulheres em situação de chefia de seus núcleos doméstico-familiares, apresentada pela maioria dos estudos, e que insiste em reforçar um perfil uniforme dessas mulheres, vistas, predominantemente, como "as mais pobres entre os pobres" (Barros; Fox; Mendonça, 1994).

* Professora da Escola de Serviço Social da Universidade Católica do Salvador e membro do Núcleo de Estudos do Trabalho da UCSal (NET). Pesquisadora associada ao NEIM Nucleo de Estudos Interdisciplinares sobre a Mulher/UFBa. Campus da Federação. Av. Cardeal da Silva, 205 - Federação - Salvador - Bahia - Brasil CEP 40.220-140.

msmacedo@superig.com.br

${ }^{1}$ Este trabalho constitui uma versão adaptada do primeiro capítulo da tese de doutorado " $N a$ trama das interseccionalidades: mulheres chefes de família em Salvador", apresentada ao Programa de Pós-Graduação em Ciências Sociais da Universidade Federal da Bahia, sob a orientação da Professora Dra. Cecilia B. Sardenberg.
Assim, falar em chefia feminina significa entender que, atualmente, essa é uma situação vivenciada por mulheres pertencentes a diferentes classes sociais e, em especial, aquelas residentes nos grandes centros urbanos. Portanto, entre outras dificuldades, a tarefa aqui proposta apresenta um duplo desafio: em primeiro lugar, romper com a associação direta e exclusiva desse fenômeno com os processos de exclusão social que terminaram por definir um perfil tradicional da chamada família "parcial" e "incompleta", chefiada por mulheres em situação de pauperização e marginalidade - como se elas pertencessem exclusivamente aos estratos mais empobrecidos da população. Em segundo lugar, traz para o centro da discussão a necessidade de repensar a predominância de estudos que tomam os vetores (i) domicílios chefiados por mulher ou ainda (ii) as mulheres chefes de família. Eles são baseados em estudos de natureza estatística, a partir da sistematização de dados sociodemográficos e de análises ensejadas por eles - especialmente, no caso do Brasil, com a divulgação de informações desagregadas dos Censos Populacionais e Pesquisa Nacional de Amostra por Domicílio, PNADs e PED 
-, e buscam, assim, compilar, descrever e detalhar informações estatísticas que cruzam indicadores e trabalham no sentido de fornecer um perfil aproximado da franca expansão desse fenômeno, sempre relacionada ao aprofundamento das desigualdades socioeconômicas e ao aumento da expectativa de vida dos brasileiros e brasileiras, associada à sobremortalidade masculina.

\section{GÊNERO E FAMÍLIA: um novo olhar em torno da chefia feminina}

A socióloga Cristina Bruschini, em um instigante trabalho intitulado "Fazendo as perguntas certas" (1996, p. 5), vai apontar a importância da reflexão teórica iniciada nos anos 1970 e aprofundada nos anos 1980 sobre as mulheres e as relações entre os sexos e, principalmente, com o amadurecimento dos marcos teóricos de gênero, pois esses, na sua opinião,

... viabilizaram o levantamento de questões pertinentes, assim como a elaboração de hipóteses e a definição de conceitos, orientando a busca de estatísticas. A invisibilidade da atividade econômica realizada pelas mulheres, o aumento do número de famílias chefiadas por mulheres, a violência doméstica, o assédio sexual são apenas alguns dos temas levantados pelo feminismo e pelos estudos de gênero, provocando a procura de dados (Bruschini, 1996, p.7).

Considero bastante pertinente a avaliação dessa autora, pois o tratamento de informações estatísticas, antes de se referir a números, "se constitui em um enunciado que reflete a representação que a sociedade tem sobre si mesma" (Oliveira, 2004, p. 5). Desse modo, os filtros de gênero podem ser claramente identificados a partir da forma como os dados são articulados e interpretados pelos analistas. Daí a tendência histórica da reprodução de estatísticas sociologicamente cegas a gênero, baseadas numa neutralidade relativa e expressa pela idéia de um homem médio ideal - o que é uma mera abstração, como o é a noção de renda per capita, por exemplo, que não fala muito das condições e qualidade de vida da maioria da população de um país, pois se baseia na idéia de um indivíduo "médio", que dificilmente pode ser representativo dos sujeitos reais, homens e mulheres, de diferentes idades, classes sociais e grupos étnico-raciais. Nesse sentido, concordo com Goldani (2000, p. 2), quando afirma que as instituições de pesquisa deveriam ter como

... preocupação central o conhecimento das dimensões plurais da vida das pessoas, tratando de identificar o melhor possível as igualdades, desigualdades e diferenças. Só assim estas pesquisas lograriam traçar um perfil mais fiel da qualidade de vida da população, suas carências e demandas.

Destarte, a crítica realizada pelos estudos de gênero vem provocando uma significativa alteração na sistemática de coleta de informações e nas formas de processamento e análise de dados. Um exemplo claro disso, nos estudos sobre família, deu-se com um conjunto de mudanças realizadas pelo Instituto Brasileiro de Geografia e Estatística - IBGE, a partir do Censo de 1980, quando o recenseador ou recenseadora recebe a instrução de atribuir ao informante a tarefa de designar a pessoa que acredita deter a chefia familiar. Outra mudança importante ocorre partir da década de 90, com as PNADs, que introduzem o conceito de "pessoa de referência" em substituição ao de "chefe do domicílio", deixando ainda ao respondente a tarefa de nominar a pessoa, homem ou mulher, responsável pelo domicílio, o que era dificultado com a noção de chefia que, pela matriz cultural dominante, era mais facilmente atribuída à figura masculina do domicílio, marido ou pai, mesmo em circunstâncias de inatividade.

Ressalte-se ainda que os estudos de gênero possibilitaram uma releitura das explicações correntes em torno de um sem número de questões acerca do universo temático das famílias, pois, ao implicar uma adesão a paradigmas críticos de análise da vida social, essas reflexões vão favorecer o entendimento de uma série de mudanças e permanências nesse campo. Entre outras questões, esses achados vão permitir que se perceba, por trás das idealizações em torno de um modelo de família, 
um conjunto de estruturas reais, o que nos obriga a admitir, em primeiro lugar, que é preciso tratar de famílias (no plural), pois há diversidade quando se fala desse grupo social, o qual está em constante mudança (e também os domicílios). Em segundo lugar, importa admitir que, embora haja solidariedade, existe ainda hierarquia, o que significa reconhecer a ocorrência de conflito e violência intrafamiliar. Por último, é necessário assimilar a existência de uma forte permeabilidade da família ao âmbito público, pois se borram, cada vez mais, as fronteiras entre o público e o privado, e a família, nesse contexto, vem se tornando objeto de intervenção das políticas públicas.

Como lembra Pinnelli (2004, p. 56), é impossível, hoje, dissociar a análise das relações de gênero e de família, pois os dois conceitos "estão interligados, sendo as mudanças em um ligadas às mudanças na outra, e estando ambos sujeitos à força das mudanças sociais”. Nessa perspectiva, portanto, é que podemos afirmar que as teorizações em torno de gênero têm-se tornado uma das principais ferramentas para a viabilização do esforço permanente de desconstrução e construção do que se convencionou chamar família, já que elas oferecem a pesquisadoras e pesquisadores um acesso a fundamentos estruturais importantes para a leitura dos múltiplos níveis hierárquicos interatuantes nesse universo - além do gênero -, tal como classe, raça ou etnia e idade ou geração. Assim sendo, tais teorizações possibilitam que se possam compreender as bases do caráter polissêmico do termo e explicar alguns dos mecanismos geradores de continuidades e de novas configurações nos padrões de comportamento e relações no universo familiar.

Algumas dessas análises (González de la Rocha, 1998; Goldani, 2000, 2002; Arriagada, 2002), ao defenderem o caráter transversal da perspectiva de gênero nas investigações sobre as diferentes afiliações institucionais de homens e mulheres, apontam a família como um dos mais relevantes contextos organizacionais, responsável, simultaneamente, pela perpetuação e transformação nas relações sociais entre os sexos. Nessa direção, o gênero vem ampliando a visibilidade de um conjunto de assimetrias e transformações no interior das famílias, relativas a aspectos fundamentais, como: (i) divisão sexual do trabalho de produção e de reprodução - e até de ócio; (ii) modalidades de divisão de poder e os processos de tomada de decisão pelos membros da família; (iii) possibilidades de exercício da sexualidade e de controle das trajetórias reprodutivas; (iv) formas de organização familiar em face do ingresso de novos membros no mundo do trabalho; e, ainda, outros fatores como (v) redução da participação em redes de solidariedade familiar e (vi) ocorrência de violência intra-familiar (Goldani, 2000).

Por outro lado, porquanto denunciam desigualdades, tais estudos também avaliam para além das permanências, ao evidenciarem a ocorrência de uma série de mudanças positivas nesse contexto. Uma das primeiras constatações é a percepção da coexistência de uma diversidade de modelos de famílias e estilos de vida, superando-se uma visão conservadora em torno da suposta "crise da família”, ou mesmo de sua extinção (Goldani, 1994). Esse novo olhar só é possível porque realiza uma leitura da articulação dinâmica de diferentes fatores que vão dar base a um conjunto transformações sociodemográficas - que passam por aspectos como fecundidade, nupcialidade, envelhecimento populacional, processos de individualização dos sujeitos sociais etc. -, permitindo que se possam entender melhor as novas formas de convivência entre as pessoas, o que envolve desde o crescimento das unióes consensuais e dos domicílios unipessoais, às novas famílias reconstituídas, ou com prole reduzida, ou mesmo as uniões entre pessoas do mesmo sexo.

Ressalte-se ainda que, por não ser gênero sinônimo de mulher, as análises iluminadas pela reflexão de gênero vão permitir que se entendam melhor as relações entre homens e mulheres, entre mulheres e entre homens no interior das famílias e as respectivas práticas e representações socialmente construídas em torno desse universo gendrado. Em que pese a persistência de relações desiguais que perpetuam efeitos perversos sobre a 
qualidade de vida das mulheres, não se pode deixar de perceber transformações nas relações de poder, as quais vão refletir uma relativa mudança nos papéis e nas responsabilidades delas, com conseqüente aumento do seu protagonismo social (Pinnelli, 2004). Entre as mudanças, destacam-se o aumento dos seus níveis de escolarização e participação no mercado de trabalho nas últimas décadas, reduzindo significativamente o modelo de provedor único (e masculino). Tais mudanças, associadas a outras transformações, particularmente de ordem demográfica, e a aspectos relacionados à subjetividade das mulheres - bem traduzidos pelo ideário em torno da emancipação feminina -, permitem constatar ainda um elevado crescimento do número de famílias chefiadas por mulheres.

Tal perspectiva de análise vai possibilitar um sem-número de descobertas e redescobertas em torno do objeto multifacetado que é a família. Fica cada vez mais evidente que um dos traços marcantes, nesse contexto de profundas transformações societárias - globalização, reestruturação produtiva, redefinição do papel do Estado perante a sociedade, precarização das garantias trabalhistas e direitos sociais etc. -, é a diversidade do que se convencionou chamar família, pois, ao mudar a sociedade, transformam-se profundamente as estruturas familiares (Goldani, 1994), numa relação de mútua influência. Assim, tornam-se a cada dia mais visíveis questões como: o aumento da heterogeneidade das estruturas familiares por tipos e etapas do ciclo de vida familiar; a diversidade de arranjos e modalidades de manutenção dos vínculos de solidariedade e subsistência; a ampliação das possibilidades de convivência intergeracional, com o prolongamento da expectativa de vida; os desafios das novas modalidades de solidariedade intergeracional, com o desmonte dos sistemas previdenciários e a escassez de empregos entre as gerações mais jovens. São essas apenas algumas das questões que atravessam o universo familiar na contemporaneidade.

Neste contexto de mudança, mulheres e homens de todas as idades ou gerações, classes e pertencimentos étnicos ou raciais - também de diferentes orientações sexuais -, são desafiados a reinventar novas modalidades de convivência e solidariedade no interior de seus grupos doméstico-familiares, especialmente com as alterações em curso nos chamados papéis masculinos. Diante da redução do poder econômico do homem, pela crise do mercado de trabalho, modificou-se o seu nível de responsabilidade e autoridade, o que, entre outros fatores, vem aumentando a ocorrência da violência intrafamiliar e tornando cada vez mais anacrônica a persistente divisão tradicional do trabalho doméstico, a qual perpetua a sobrecarga das mulheres - particularmente num momento em que cresce significativamente sua participação como trabalhadora remunerada e, conseqüentemente, como co-provedora ou chefe de família com provisão exclusiva. Assim, as mulheres chefes de família constituem uma situação paradigmática da equação gênero e família e das possibilidades abertas pelo uso do primeiro termo como explicativo do segundo, como veremos a seguir.

\section{TRAJETÓRIA DOS ESTUDOS SOBRE O FENÔMENO DA CHEFIA FEMININA}

O fenômeno da chefia de domicílios por mulheres constitui uma nova realidade, como insistem em afirmar as assustadas e preocupadas manchetes de jornais e os programas de televisão. Certamente, porém, sua existência tem sido ocultada por um retrato uniforme das formas de organização familiar no Brasil, favorecido, durante muito tempo, pela universalização do protótipo da família conjugal nuclear (Corrêa, 1982). Dessa forma, o que pode ser considerado como novo nesse contexto? Por certo, é a sua expansão entre as chamadas camadas médias brasileiras, o que, do ponto de vista ideológico, vem se chocando com o modelo dominante nesse universo, imposto pelas ideologias de gênero - que prevêem uma distribuição de papéis e responsabilidades segundo hierarquias baseadas em fatores como sexo e idade dos membros, atribuindo ao homem e aos de maior idade maiores poderes e prerrogativas no interi- 
or do grupo doméstico. Mas a grande novidade da expansão de seu interesse no campo das pesquisas (com alguns reflexos também no campo da intervenção, embora, neste caso, os motivos sejam bem mais amplos), dirão Woortmann; Woortmann (2002), baseia-se no fato de que

... tendo o fenômeno penetrado na própria camada social dos pesquisadores (ou melhor dizendo, das pesquisadoras), foi ele como que redescoberto e revalorizado, na medida em que deixou de ser algo característico de um "outro", para se tornar presente entre "nós” (p.2).

Assim, as três últimas décadas testemunharam uma significativa expansão do fenômeno em todos os estratos sociais e, conseqüentemente, o crescimento de sua visibilidade social. Revisitando a vasta literatura sobre a temática no Brasil, o que foi confirmado por um amplo levantamento realizado em torno dos estudos sobre o tema (Scott, 2002a; Woortmann; Woortmann, 2002) e por importantes expoentes que se voltaram para a reflexão em torno da sua expansão na América Latina (Safa, 1998; Gonzalez de la Rocha, 1999; Arriagada, 2002; Oliveira; García, 2004), tenho me dado conta da amplitude das questões que envolvem os estudos sobre os chamados novos arranjos familiares e, particularmente, aqueles em torno da situação de chefia domiciliar feminina.

Esses estudos apresentam reflexões que envolvem uma pluralidade de questões, fundamentais para a consolidação dessa temática no campo dos estudos sobre família no Brasil. Importa, então, destacar a contribuição pioneira de Barroso (1978) e Figueiredo (1980), que vão apontar para a necessidade de se dar atenção ao fenômeno em expansão da chefia feminina e a importância desses novos arranjos para a manutenção de famílias de classe trabalhadora. Mas, nesse processo, outros estudos, de natureza mais histórica, vão buscar refletir que o fenômeno da chefia feminina não constitui uma problemática completamente nova no Brasil, sendo um arranjo recorrente no século XIX, logicamente que entre as famílias menos abastadas em importantes estados do país como São Paulo (Dias, 1984) e a Bahia (Mattoso, 1988; Borges,
1992); outros estudos, posteriormente, vão corroborar esses achados (Costa, 1998; Samara, 2002). Com efeito, a década de 80 e os anos 1990 vão testemunhar todo um processo de desconstrução do olhar sobre as formas de organização familiar no Brasil, o que implicava a crítica à generalização do modelo das classes dominantes da família patriarcal (Corrêa, 1982). Essa crítica permitirá a consolidação de uma nova perspectiva, a partir da incorporação das análises de gênero, para se pensar a família e o lugar da mulher nesse contexto, inclusive com a reflexão a respeito da importância do entrelace de desigualdades com a questão étnico-racial (Goldani, 1991). Dessa forma, ao trazerem à luz um conjunto de transformações geradoras de "convergências e divergências nas estruturas familiares no Brasil" (Bilac, 1991), esses novos estudos terminam por ampliar a visibilidade dos chamados "arranjos familiares não-canônicos” (Berquó; Oliveira; Cavenaghi, 1990; Berquó; Oliveira 1990) e, com eles, ganham ainda maior projeção as pesquisas voltadas para a compreensão das famílias com chefia feminina, especialmente aquelas que decodificavam as recentes mudanças na estrutura sociodemográfica do país (Neupert; Calheiros; Turchi, 1988) e que já estabeleciam uma relação entre chefia feminina e processos mais amplos de pauperização da população urbana (Barros; Fox; Mendonça, 1994).

O avanço da produção de pesquisas em torno do tema vai se beneficiar da consolidação de importantes associações científicas nacionais, como a Associação Brasileira de Estudos Populacionais (ABEP), a Associação Brasileira de Estudos do Trabalho (ABET), a Associação Nacional de PósGraduação e Pesquisa em Ciências Sociais (ANPOCS), a Associação Brasileira de Antropologia (ABA) e a Associação Brasileira de Sociologia (SBS). Como lembra Scott (2002a), essas associações, através dos seus encontros nacionais e do debate por eles ensejados, além das publicações de seus anais, "tornam visíveis e públicas", a partir de diferentes perspectivas - a demográfica, a sociológica, antropológica, a das relações de traba- 
lho e as discussões de caráter social mais amplo-, as análises de um conjunto de questões fundamentais, relacionadas direta ou indiretamente à discussão em torno da temática da chefia familiar feminina, como mulher e trabalho, mulher e pobreza, arranjos familiares e divisão sexual do trabalho.

Assim, de forma panorâmica, é possível a identificação de uma vasta produção que vai transitar por diferentes perspectivas, destacando-se, principalmente, aquelas que tomam como referência a sistematização de dados originados dos levantamentos de caráter censitário e por pesquisas baseadas em amostras domiciliares relacionadas à chefia feminina no Brasil, nas últimas décadas (Castro, 1989; Oliveira, 1992; Cioffi, 1998; Medeiros; Osório, 2000; Berquó, 1998, 2002; Oliveira; Sabóia; Soares, 2002). Outros trabalhos buscarão, a partir de um recorte geográfico e uma abordagem mais situada - através de pequenos levantamentos tipo survey, ou de trabalhos mais qualitativos, via ao uso de etnografias, entrevistas e observação em campo -, reconstruir esse universo a partir da articulação entre as dimensões objetiva e simbólica que constituem a vida desses sujeitos (Machado Neto, 1979; Salem, 1981; Fonseca, 1987; Scott, 1990a; Agier, 1990, Macêdo, 1999; Mendes, 2002).

As temáticas discutidas nesses trabalhos cobrem um amplo espectro de questões e, mesmo correndo um sério risco de cair em simplificação excessiva desse universo, arrisco-me a pensá-lo basicamente em três grandes blocos. Em primeiro lugar, estão as análises que incorporam uma reflexão de natureza mais antropológica em torno da monoparentalidade e matrifocalidade (Neves, 1985; Woortmann, 1987; Carvalho; Cravo, 1988; Scott, 1990b; Vitale, 2002; Hita, 2004) e, em segundo lugar, estão aquelas que propiciam uma discussão de caráter mais sociológico, voltada para a problematização de questões relacionadas à adequação da terminologia utilizada, tal como "responsabilidade", "chefia", "gerência" ou ainda "provisão" e dos significados atribuídos aos termos ou expressões como "manutenção econômica", "pessoa de referência”, "autoridade e atribuições", "prerrogativas e deveres" (Carvalho, 1998a; Marteleto,
1998; Piola; Osório, 2002; Oliveira; Sabóia; Soares, 2002; Oliveira, 2005b). Por fim, há as análises que buscam pensar o fenômeno de modo relacionado às questões estruturais, como os processos de precarização laboral, desemprego e pauperização e sua relação com o aumento dos domicílios chefiados por mulheres (Santos, 1996; Castro, 1991; Novelino, 2002; Mendes, 2004; Oliveira, 2005a; Carloto, 2005; Montali, 2006), bem como à necessidade da proposição de políticas públicas voltadas para essa população (Carvalho, 1998b; Scott, 2002b; Souza, 2000; Oliveira, 2002; Novelino, 2004).

A partir dessa visão panorâmica, portanto, parece ser bastante plausível afirmar que o que vai assegurar relevância e a visibilidade social aos estudos sobre as famílias chefiadas por mulheres, ou ainda ao vetor mulheres chefes de família, não parece ser apenas o relativo crescimento estatístico desse tipo de arranjo (Scott, 2002a, p.2) - como veremos a seguir -, mas a complexidade de uma pluralidade de fatores que se articulam para a constituição dessa problemática. Significa dizer que é preciso entender como a precarização das condições de vida da população - através do entrelace de questões como a reestruturação produtiva, as redefinições nas regras do mercado de trabalho e no papel do Estado - articulam-se a fatores demográficos - como a ocorrência de novos fluxos migratórios, a redução da fecundidade, o aumento do número de divórcios, a ampliação da expectativa de vida (associada à manutenção das taxas de sobremortalidade masculina) e o crescimento relativo das uniões consensuais e das chamadas "produções independentes" -, o que resulta em novos arranjos do tipo monoparental.

Sendo assim, a combinação de fatores objetivos - como a ampliação da entrada da mulher no mercado de trabalho nas três últimas décadas com as profundas transformações nas subjetividades, num contexto de globalização e avanço de movimentos sociais e de novos protagonistas sociais, como o movimento feminista, vai produzir uma situação de grande complexidade, reafirmando a idéia de que a ampliação dos domicílios com chefia feminina é um processo multideterminado e, por- 
tanto, também, multifacetado. Daí se afirmar que as famílias chefiadas por mulheres precisam ver vistas como o resultado, como lembra Berquó (2002, p.245), de um conjunto de "transformações econômicas, sociais, culturais e comportamentais que vão se sucedendo ao longo do tempo", e que produzem variações nas trajetórias das mulheres, fazendo que essa chefia possa ter múltiplos significados, tais como a situação da mulher solteira, viúva ou separada com filhos, ou daquela que pode ser casada e estar coabitando com companheiro e filhos, ou encontrar-se nessas mesmas condições e ainda estar vivendo com parentes e outros agregados.

Por fim, importa ainda destacar algumas informações relevantes para se entender o mosaico de fatores relacionados à constituição do fenômeno da chefia de núcleos doméstico-familiares por mulheres no Brasil. Assim, os dados da Síntese dos Indicadores Sociais (IBGE, 2007) totalizaram, para a chefia feminina no país, em 2006, um percentual de $29,2 \%$, enquanto a masculina é de 70,8\%. Observe-se que, no primeiro caso, o percentual de chefes sem cônjuge é de $79,3 \%$, enquanto que, no segundo caso é de apenas 5,6\% - um dado importante para se entender porque a chefia masculina se dá em condições mais favoráveis: não apenas a força de trabalho masculina possui um nível de remuneração mais elevado que a feminina na esfera da produção, mas também possui maciçamente a chance de contar com cônjuge, na condição co-provedora ou de responsável por grande parte do trabalho de reprodução do grupo doméstico (quando não é quem se ocupa dele como um todo). Essa pesquisa registrou ainda, no caso da Bahia, contingente de 31,9\% de chefia feminina, enquanto que, na Região Metropolitana de Salvador, esse percentual se eleva para a marca de 43,8 do total de famílias, constituindose numa das mais altas entre as áreas metropolitanas do país. Assim, nesse contexto, uma das questões emergentes nos estudos sobre mulheres sem cônjuge na condição de chefes de seus domicílios é a difusão de uma noção de feminização da pobreza, diretamente relacionada à ampliação desse fenômeno, o que demanda uma intervenção de organizações públicas e privadas em torno dessa problemática. Tal intervenção certamente exigirá um esforço de problematização, no sentido de se discutir até que ponto domicílios chefiados por mulher vão significar, necessariamente, o comprometimento da qualidade de vida do conjunto de seus membros.

\section{PROBLEMATIZANDO O DEBATE EM TORNO DA FEMINIZAÇÃO DA POBREZA}

O contato com estudos e pesquisas voltados para entender a diversidade de arranjos familiares tem trazido à tona, cada vez com mais freqüência, a discussão em torno da questão da elevação da precariedade socioeconômica das famílias chefiadas por mulheres. Essa perspectiva parece, a cada dia, estar se tornando central quando o tema é família e provisão domiciliar feminina. $\mathrm{O}$ que pude constatar é que a grande maioria dos estudiosos dessa temática enfatiza a questão da vulnerabilidade socioeconômica como elementochave para o entendimento da situação vivenciada pelas mulheres chefes de família, denunciando as "estreitas margens de viabilidade" dos domicílios situados nesse contexto (Buvinic; Lycette; McGreevey, 1983; Barros; Fox; Mendonça, 1994; Novelino, 2002, 2004; Belchior, 2007). Por outro lado, defendo que é preciso problematizar o risco da generalização de leituras que reforçam estereótipos de vulnerabilidade e pobreza, homogeneizadores de uma realidade que - sem negar as dificuldades objetivas enfrentadas por esse grupo social - não é monocromática e demanda, portanto, uma análise capaz de reconhecer a existência de uma complexidade que não pode ser contida em modelos estereotipados como "mais pobre entre os pobres" (Lavinas, 1996; González de la Rocha, 1999).

Nessa perspectiva, em que pese a importância da ênfase na questão das desigualdades sociais como eixo central nas análises em torno da expansão do fenômeno da chefia de domicílio por mulheres, começam a ganhar espaço outras vozes 
que enfatizam a necessidade do entendimento de que tal fenômeno, por estar sujeito igualmente a outros condicionantes, "deve ser visto como uma configuração histórica e social” (Carvalho, 1998a, p.7). Isso vai significar a ruptura com qualquer tendência à adoção de explicações reducionistas e simplificadoras de processos multideterminados e historicamente situados, os quais demandam, portanto, uma leitura que interconecte as desigualdades como as de gênero, classe, raça ou etnia e idade ou geração à questão da relação com o Estado, particularmente no que se refere à oferta de políticas públicas.

No caso dos estudos sobre domicílios com chefia feminina, como apontado anteriormente, não se pode negar que a adoção do viés de gênero vai ser um dos fatores determinantes na discussão e na reorientação das análises acerca dessa problemática. Em primeiro lugar, por permitir uma releitura da matriz cultural dominante, atravessada fortemente pelas hierarquias de gênero, que marcam a tônica dos discursos em torno desses sujeitos. Isso ocorre porque a mulher, nessa condição, é vista quase sempre como um contraponto ao modelo da chefia domiciliar masculina - ainda assentado no referencial dominante da unidade nuclear, composta pelo casal heterossexual, unido legalmente e com filhos. Assim, a crítica que se pode fazer é que as unidades domiciliares com chefia feminina, longe de representarem uma exceção, são "formas não nucleares [que] devem ser vistas e entendidas como parte de uma complexa reconfiguração que as famílias (no plural) experimentam [...] no mundo inteiro" (Gonzalez de la Rocha, 1999, p.127).

Em segundo lugar, as análises de gênero possibilitam entender o que faz com que nove entre cada dez famílias do tipo monoparental sejam chefiadas por uma mulher. A referida crítica à matriz cultural dominante, possibilitada pela perspectiva de gênero, evidencia que ainda são preservados modelos mais ou menos rígidos em torno das expectativas acerca da maternidade ou maternagem e paternidade ou paternagem, em que a "ética do cuidado” (Scavone, 2001) é supervalorizada, o que faz com que o filho ainda seja, prioritariamente, objeto de cuidados da mãe. Assim, as ideologias de gênero são a base para se entender o que vai definir a identidade primeira desse grupo - mulher, depois, chefe de família. Inclusive, é o principal fator que lhes define um "lugar" no mundo: tornam-se chefes de família porque são mães, num contexto social que prevê um modelo de maternidade ou maternagem, socialmente construído, baseado na hipertrofia de suas responsabilidades parentais (Scavone, 2001).

Do mesmo modo, retomando as conexões entre famílias e desigualdades sociais, as análises de gênero, a partir dos anos 1980, vão fornecer ferramentas para a realização de uma série de estudos que, ao procederem a uma avaliação de um conjunto de indicadores estatísticos sobre o crescimento da pobreza no mundo, terminaram por identificar um amplo contingente de mulheres entre a população mais pauperizada nos países pobres. O clássico e já citado trabalho organizado por Buvinic, Lycette e McGreevey (1983), intitulado Women and poverty in the Third World, tornou-se uma referência obrigatória nos trabalhos sobre a situação das mulheres e seu difícil acesso aos recursos existentes nos países do chamado Terceiro Mundo. A divulgação de pesquisas dessa natureza vai inspirar um conjunto de políticas que, mais tarde passa, a ser chamado de Programas de Gênero e Desenvolvimento, implementados por agências internacionais, as quais atribuem a um processo de feminização da pobreza a identificação das mulheres com “a grande massa da pobreza mundial”.

Com relação a esse processo, Chant (2004) vai comentar que se criou, a partir daí, um "tema ortodoxo”, pois se formou um grande consenso entre os pesquisadores da área, o que serviu para fornecer "combustível para uma ampla agenda de programas” e políticas públicas que terminou por levar a uma segunda constatação: de que, entre as populações pauperizadas, as mulheres chefes de família comporiam a maior parte do seu contingente mais vulnerável, isto é, elas se tornaram "as mais pobres entre os pobres” (Barros; Fox; Mendonça, 1994). 
Portanto, não custa relembrar o quanto tem sido importante o amplo reconhecimento da transversalidade de gênero como uma categoria de grande valor heurístico para a análise de uma série de desigualdades que atravessam a vida de homens e mulheres, como relações de poder; o que evidencia as desvantagens vivenciadas por mulheres em todo mundo, especialmente quando intersectadas por fatores como classe, raça ou etnia e idade ou geração. Mas, por outro lado, faz-se ainda necessário ressaltar que os usos de gênero especialmente quando o termo é utilizado simplificadamente como sinônimo de mulher-, como qualquer ferramenta de análise, ao apresentarem um sem-número de possibilidades, também trazem, em seu bojo, certos riscos, como o de se naturalizarem as desigualdades em torno de algumas populações, como se essa condição lhes fossem intrínsecas em decorrência de um conjunto de características particulares desfavoráveis. O que vai significar, em última instância, responsabilizálas pelo "seu" gap.

Em que pese todo um conjunto de esforços envidados para se entender a situação dos domicílios chefiados por mulher, permitindo a consolidação de uma nova legitimidade em torno do fenômeno, tal perspectiva termina por reforçar uma ênfase excessiva nos aspectos socioeconômicos, tornando incontestável o dado sobre a maior pobreza das mulheres chefes de família. Acredito que, a despeito das possibilidades abertas pela discussão realizada em torno da feminização da pobreza, no tocante à ampliação da visibilidade social desses domicílios e à abertura de espaço para esses sujeitos tornarem-se "pauta" dentro da agenda dos programas de desenvolvimento e de políticas públicas - como a desenvolvida sob orientação do Banco Mundial, por exemplo -, não se pode deixar de considerar o outro lado da moeda apresentado por tal enfoque: a associação negativa entre chefia feminina e pobreza, como se o crescimento desses domicílios fosse símbolo de quebra dos valores familiares e da desorganização familiar; portanto, de uma situação de retrocesso no ciclo ideal de desenvolvimento da família. A este res- peito, diz Safa:

A visão negativa das unidades domésticas chefiadas por mulheres é em parte conceitual, devido a nossa ênfase eurocêntrica na família nuclear como a norma e a encarnação da modernidade e do progresso [...]. Esta visão patológica das unidades domésticas chefiadas por mulheres contribui para a crença de que estas geram pobreza; em lugar de vê-las como um resultado dela, e um resultado, por acréscimo, em que as políticas neoliberais têm desempenhado um papel destacado (Safa, 1999, p.9, tradução da autora).

Ressalte-se ainda que, no caso dos países desenvolvidos, a formulação acima permite uma leitura de que a eleição das mulheres chefes de família (vista nesses países como single mothers) como objeto de políticas sociais termina por ganhar conotação negativa, reforçando discriminações, pois, ao serem convertidas em beneficiárias de direitos sociais, tornam-se alvo de ataques como símbolo de abuso do sistema do Welfare State principalmente na Inglaterra e nos Estados Unidos. Alguns autores vão afirmar que essa forte relação entre feminização da pobreza e chefia feminina de domicílios vai criar a "culture of single motherhood", o que vem sendo chamado, em alguns círculos, de "Novo Paradigma da Pobreza" (Thomas apud Chant, 2004, p.20).

Observe-se, porém, que qualquer esforço de problematização da questão da chamada feminização da pobreza vai requerer do analista ou da analista uma abordagem extremamente cuidadosa e equilibrada. Em primeiro lugar porque essa noção está assentada em dados objetivos, pois, como lembra Moghadam (1997), as mulheres efetivamente estão em situação de desvantagem em relação aos homens, tanto no que se refere ao usufruto de direitos quanto à carga de trabalho e ao nível de remuneração. Têm desvantagens ainda em relação à possibilidade de mobilidade socioeconômica, já que enfrentam barreiras culturais, legais, obstáculos no mercado de trabalho, entre outras limitações. Portanto, a desigualdade de gênero não é fictícia, pois as mulheres chefes de família enfrentem dificuldades suplementares, ao terem que administrar sua dupla participação nas esferas da produção e da reprodução, em condi- 
ções desfavoráveis quando comparadas aos homens que também são chefes de domicílio e que, na sua maioria, contam com a participação, cada vez maior, das esposas, tanto na tradicional esfera dos cuidados domésticos como no mundo da produção.

Em segundo lugar, um dos raciocínios mais óbvios para explicar a vulnerabilidade dos domicílios com chefia feminina é, na maioria deles, a ausência da figura do esposo-pai, que, como lembra Agier (1990, p. 49), "é uma força de trabalho que não é exatamente substituível pela força de trabalho feminina”. Assim, a premissa de que a perda da figura do principal provedor, reconhecido hipoteticamente como portador mais provável de características socialmente mais valorizadas na relação com o mercado de trabalho, com seu entorno e no próprio grupo doméstico, leva, conseqüentemente, à lógica conclusão da impossibilidade de as mulheres cumprirem bem as obrigações do chefe da família, já que se trata da transferência desse papel para alguém destituído dos atributos desejáveis ao enfrentamento da dupla condição de provedor e responsável pelo domicílio.

Portanto, nessa linha de raciocínio, a chefia feminina vai significar, quase sempre, para os grupos domésticos, uma agudização dos seus níveis de subsistência, pois pressupõe uma impossibilidade de as mulheres oferecerem condições adequadas à manutenção dos seus domicílios. Em tal contexto, a situação de privação vai ser transferida para as crianças e outros membros, pelo fato de as mulheres não apresentarem condições de garantir os mesmos níveis de subsistência da chefia masculina. Sob essa perspectiva, então, “famílias monoparentais femininas e pobreza acabam, de um lado, por construir outro estigma, o de que as mulheres são menos ‘capazes' para cuidar de suas famílias ou para administrá-las do que um homem...” (Vitale, 2002, p.51). Observe-se, porém, que a crítica realizada por Castro (2001, p.92) é bastante elucidativa acerca dos reais motivos das desvantagens sociais enfrentadas pelas mulheres, nesse contexto:

As mulheres de famílias monoparentais [...] foram esposas, ou seja, empobrecem não porque se tornam chefe de família, porque deixaram de ter um provedor, mas, com a maior probabilidade, porque foram esposas antes e, assim, não tiveram as mesmas oportunidades dos homens, casados ou vivendo sós, ou das mulheres sós, de investir em carreira, de socializar-se com as regras do e no mercado.

Em que pese uma série de argumentos contrários, não há como negar que a ênfase excessiva na vulnerabilidade dos domicílios com chefia feminina, contida na perspectiva de análise da feminização da pobreza, termina por reforçar estereótipos e por provocar um alto nível de estigmatização das unidades domiciliares e dos sujeitos que se encontram nessa situação. O próprio movimento feminista realiza uma crítica a essa perspectiva e propõe a adoção da expressão pauperização das mulheres, questionando-se: por que “associar 'feminização', palavra culturalmente desvalorizada, à palavra 'pobreza', também socialmente depreciativa? Por que não falar [...] em ‘pauperização das mulheres'?” (Bruschini et al apud Farah, 2004, p. 55). Outro argumento que contribui para essa crítica é oferecido por Safa (1999), quando reflete que as unidades domésticas chefiadas por mulheres não se materializam num fenômeno relacionado unicamente à pobreza e à economia. Assim, a própria noção de vulnerabilidade pode ser também problematizada, no momento em que se questiona a idéia de viabilidade econômico-social baseada exclusivamente em fatores como uma inserção satisfatória no mercado de trabalho e o recebimento de rendimentos compatíveis.

Medeiros e Osório (2000) vão contestar a hipótese de que haja qualquer padrão de feminização da pobreza no Brasil no período de 1983 a 2003, diferenciando esse processo da chamada sobre-representação, por se tratarem de dois fenômenos distintos. Para esses autores, não houve um aumento da desigualdade no acesso a recursos entre homens e mulheres que possa ser caracterizado como um típico processo de feminização da pobreza, inclusive entre mulheres chefes de família. Afirmam, portanto, que o que ocorre é uma histórica sobre-representação das mulheres entre os pobres, por uma pluralidade de 
fatores e que passa logicamente pelo entendimento das desigualdades de gênero. Assim, se há mudanças nos padrões demográficos na população brasileira que têm levado ao aumento das mulheres chefes de família e elas se tornam chefes principalmente por serem mães, é a combinação dessa sobrerepresentação entre os pobres e a presença de filhos que gera a idéia de uma feminização da pobreza. Mas elas estão mais fragilizadas porque assim já se encontravam em relação aos homens e por terem filhos - fenômeno que não acontece entre as mulheres chefes que não possuem filhos, principalmente crianças menores de 15 anos.

González de la Rocha (1999, p. 33), por sua vez, oferece uma leitura bastante crítica acerca da anteriormente alegada inviabilidade dos domicílios comandados por mulheres. Essa autora vai defender a necessidade de se "entender a complexidade destes domicílios e a diversidade de respostas ante as dificuldades econômicas". Principalmente porque o processo de diversificação das estruturas familiares vai provocar a construção de novos "cenários sociais onde se podem observar mudanças nas relações sociais, nos padrões de socialização e nos padrões de geração e uso dos recursos" (p. 34), e também na distribuição de responsabilidades. Tal perspectiva se coaduna com as constatações de alguns estudos sobre famílias das classes trabalhadoras, pois há diferenças nas prioridades de alocação de recursos entre os chefes de diferentes sexos, sendo que a chefia feminina é muito mais democrática em relação às necessidades do conjunto de seu grupo doméstico (Carvalho, 1998a; Macêdo, 1999). Isso permite inferir que o montante de recursos percebido pelo chefe pode não ser o fator determinante do nível de vida do grupo, mas, principalmente, a forma de alocação desses recursos.

Entretanto, note-se que é sempre arriscado explicitar certas formulações, à primeira vista quase essencialistas, por parecerem cair na análise simplista de defesa do "altruísmo das mulheres" em oposição ao "egoísmo masculino" (Macedo, 1999). Porém o que vem se constatando - em estudos como os realizados por Carvalho (1998a),
Arriagada (2002) e Oliveira e García (2004) - é que, em muitas situações, os rendimentos dos homens são direcionados para dispêndio pessoal, reduzindo-se inclusive "os níveis de regularidade dos recursos e trazendo vulnerabilidade e "pobreza secundária' para mulheres e crianças” (Chant, 2004, p. 21). Assim, esses estudos, ao discutirem as diferenças na distribuição de recursos nos domicílios com chefia masculina e feminina, vão apontar que as mulheres chefes investem a grande maioria do seu ganho (quando não todo) na manutenção do domicílio, o que, ao contrário do que se pensa, traz efeitos altamente positivos para fatores como melhoria dos níveis nutricionais, dos cuidados de saúde e de educação dos membros da família. Observe-se, desse modo, que, mesmo com ganhos mais reduzidos que aqueles com chefia masculina, os domicílios comandados por mulheres têm uma maior inversão de rendimentos voltados para o conjunto do grupo doméstico, além de, em alguns casos, poder contar com a contribuição de outros membros e com acesso à participação em redes sociais de apoio familiar e a recursos externos ao grupo, como a inclusão em programas sociais.

Assim, é fundamental que as análises em torno da relação entre chefia feminina e pobreza levem em consideração outros indicadores de bem estar para dimensionar os níveis de qualidade de vida dos domicílios chefiados por mulheres (Oliveira; García, 2004). Tal preocupação tem fundamento, porque, como lembra Lavinas (1996), a ênfase em gênero, de um lado, e em aspectos econômicos, de outro, não tem sido suficiente para explicar o chamado fenômeno da feminização da pobreza e sua prevalência entre as mulheres chefes de família. Em primeiro lugar, porque, em se tratando de população das camadas mais pobres, a distância em termos de renda entre homens e mulheres vem diminuindo - especialmente com as redefinições do mercado de trabalho e a escassez de empregos que têm atingido maciçamente o contingente masculino da força de trabalho. Em segundo lugar, porque aumentaram muito as disparidades de renda entre as próprias mulheres, isto é, entre ricas e pobres; o que reforça a 
necessidade de levar outros aspectos em consideração, como a etapa do ciclo de vida, o pertencimento a grupo de idade ou geração ou também raça ou etnia, interessando ainda entender a participação em redes de apoio e solidariedade, a natureza do vínculo mantido pelas mulheres (ou a inexistência dele) com o pai das crianças, entre outros fatores.

\section{CONSIDERAÇÕES FINAIS}

Dessa forma, o que pude perceber é que ainda são escassos os estudos que se propõem a investigar a diversidade de situações agrupadas sob a denominação de chefia feminina e, particularmente, no que se refere à sua recente ampliação entre as famílias pertencentes aos estratos médios das grandes áreas metropolitanas. Menos ainda se conhece, em termos mais qualitativos, acerca de como a situação de chefia vem sendo vivenciada por mulheres em diferentes segmentos sociais -o que significará poder compreender, entre outros aspectos, a diversidade de trajetórias que termina por levá-las à condição de provedoras de seus domicílios e, a partir daí, questões como a forma como essa experiência vem influenciando suas relações objetivas e subjetivas com o mercado de trabalho, suas modalidades de organização doméstico-familiar, seus vínculos interpessoais e afetivos, suas possibilidades de concretização de projetos pessoais e os processos de construção de suas subjetividades ou identidades, entre outros fatores.

Urge, portanto, a realização de pesquisas que busquem desvendar como se dá o entrelace de uma série de desigualdades e discriminações nas experiências dessas mulheres e de que maneira são conformadas suas opções e alternativas de vida, sem, no entanto, cair numa perspectiva de vitimização dos sujeitos inseridos nesse contexto. Daí a necessidade de utilização de ferramentas analíticas e operacionais que permitam o desvelamento das mudanças e permanências nos processos sociais e nas formas de sociabilidade em torno desse grupo social - o que vai implicar ir além da definição de um recorte empírico e de uma opção teórico-metodológica, pois, envolve um conjunto de escolhas, que passam principalmente por ter clareza quanto à adesão a uma determinada perspectiva epistemológica e, principalmente, ontológica que oriente o esforço de investigação científica desse objeto.

Com esses questionamentos, busco deixar clara a relevância, para o estudo do fenômeno da chefia familiar feminina, da adesão a uma epistemologia feminista - que realiza uma crítica des-construcionista da teoria social e tem um olhar assumidamente situado num ponto de vista - e a uma ontologia relacional. O que significa, em primeiro lugar, trabalhar com gênero como uma categoria política, como relações de poder-logicamente que articulada a outras dimensões como classe, raça ou etnia e idade ou geração - e ainda por considerar, "na linha do raciocínio aqui desenvolvido, [que] a história das pessoas consiste na história de suas relações sociais" (Saffioti, 2002, p. 2). Em segundo lugar, por acreditar que uma perspectiva relacional assume que a possibilidade de desvelamento da realidade depende da adoção de uma postura que reconheça a necessidade da articulação entre as dimensões objetivas e subjetivas da vida social, pensando a "subjetivação enquanto movimento inseparável da objetivação” (p. 2).

Acredito que, nessa perspectiva, a reflexão sobre a experiência de chefia domiciliar por mulheres permitirá captar a dinâmica que as envolve, fazendo com que sejam vistas como indivíduos mobilizados por processos estruturais, mas que, ao mesmo tempo, também atuam como sujeitos de suas vidas, ao mobilizarem processos de ação e significação da realidade social. Como lembra Goldani (1994, p.326), “ao construir suas trajetórias, as mulheres chefes ou não de família não são recipientes passivos das mudanças e vítimas de forças estranhas a elas [...], apesar de sujeitas a restrições, têm suas próprias resistências e lutas”. Por fim, creio que pensar o contexto plural das mulheres chefes de família hoje pode contribuir para ampliar essa reflexão, mostrando que há diversidade de situações suscitadas por essa condi- 
ção e permitindo compreender que a interação de diferentes marcadores sociais vai gerar uma diversidade de questões entre mulheres que vivem sob a mesma rubrica, para além da fórmula mulher, pobre e chefe de família.

(Recebido para publicação em fevereiro de 2008) (Aceito em junho de 2008)

\section{REFERÊNCIAS}

AGIER, Michel. O sexo da Pobreza: homens, mulheres e família numa "avenida" em Salvador da Bahia. Tempo Social: revista Sociologia USP, São Paulo, v.2, n.2, p.3560, 1990.

ARRIAGADA, Irma. As famílias e as políticas públicas na América Latina. In: PRÉ-EVENTO MULHERES CHEFES DE FAMILIA: crescimento, diversidade e políticas. Ouro Preto: CNPD, FNUAP e ABEP, 2002, 29p. Disponível em: www.abep.nepo. unicamp.br/XIIIencontro/arriagada.pdf. Acesso em: 18 set., 06.

BARROS, Ricardo; FOX, Louise; MENDONÇA, Rosane. Pobreza e domicílios chefiados por mulheres. In: SEMINÁRIO NACIONAL POLÍTICAS ECONÔMICAS, POBREZA E TRABALHO, 2. Rio de Janeiro: IPEA, 1994, p.79-85.

BARROSO, Carmen. Sozinhas ou mal acompanhadas: a situação das mulheres chefes-de-família. In: ENCONTRO NACIONAL DE ESTUDOS POPULACIONAIS, 1., Anais... Campos do Jordão, ABEP, 1978.

BELCHIOR, João Raposo. Chefia Feminina: feminização e transmissão intergeracional da pobreza. Rio de Janeiro, 2007. 102f. Dissertação (Mestrado em Estudos Populacionais e Pesquisas Sociais) - Escola Nacional de Ciências Estatísticas. Disponível em: www.ence.ibge.gov.br/pos graduacao/ $\mathrm{m}$ e s t r a d o d i s s e r t a c o e s/p d f / 2007 joao_raposo_belchior_TC.pdf. Acesso em: 08 jan., 2008. BERQUÓ, Elza; OLIVEIRA, Maria C. Família no Brasil: análise demográfica e tendências recentes. Ciências Sociais Hoje, São Paulo, Vértice/ANPOCS, p.30-64, 1990.

; CAVENAGHI, Suzana M. Arranjos familiare' "não-canônicos" no Brasil. In: ENCONTRO NACIONAL DE ESTUDOS POPULACIONAIS DA ABEP, 7. Anais, Caxambu: ABEP, 1990. v.1, p.99-136.

- Uma visão demográfica dos arranjos familiares no Brasil. In: SCHWARTZ, Lilia Moritz. (Org.). História da vida privada no Brasil: contrastes da intimidade contemporânea. São Paulo: Companhia das Letras, 1998, v. 4. p.411-437.

Perfil demográfico das chefias femininas no Brasil. In: BRUSCHINI, Cristina; UNBEHAUM, Sandra G. Gênero, democracia e sociedade brasileira. São Paulo: FCC: Ed. 34, 2002. p.243-265.

BILAC, Elizabete Dória. Convergências e divergências nas estruturas familiares no Brasil. Ciências Sociais Hoje, São Paulo, Vértice/ANPOCS, p.70-94, 1991.

BORGES, Dain. The family in Bahia, Brazil, 1870-1945. Stanford, California: Stanford University Press, 1992.

BRUSCHINI, Cristina. Fazendo as perguntas certas: como tornar visível a contribuicão econômica das mulheres para a sociedade? In: CONGRESSO LATINOAMERICANO DE
SOCIOLOGIA DO TRABALHO, 2. Águas de Lindóia, dez. 1996, 15p.

BUVINIC, Mayra; LYCETTE, Margaret; McGREEVEY, William P. Women and poverty in the Third World. Baltimore/ London: The John Hopkins University Presss, 1983.

CARLOTO, Cássia. M. A chefia familiar feminina nas familias monoparentais em situação de extrema pobreza. Revista Virtual Textos e Contextos, Porto Alegre, PUC 2005 , 17p. Disponível em: http://revistaseletronicas.pucrs.br/ojs/ index.php/fass/article/view/994. Acesso em: 20 set,. 2006

CARVALHO, Maria Luiza Santos. A mulher trabalhadora na dinâmica da chefia familiar. Estudos Feministas, Rio de Janeiro, IFCS/UFRJ, v. 6, n.1, p.7-33,1998a.

Famílias chefiadas por mulher: relevância para uma política social dirigida. Serviço Social e Sociedade, [S.l.], n.57, p.74 -98, jul., 1998b.

CARVALHO, Marília; CRAVO, Veraluz Zicarelli. Antes mal acompanhada do que só: estudo de relações familiares em grupos matrifocais. Boletim de Antropologia, Curitiba, v.1, n.3, p.23-44, abr., 1988.

CASTRO, Mary Garcia. Family, gender and work: the case of female heads of household in Brazil (São Paulo and Bahia - 1950 /1980). 1989. Tese (Doutorado) - University of Florida. Gainesville, Florida, 1989.

Mulheres chefes de família, racismo, códigos de idade e pobreza no Brasil (Bahia e São Paulo). In: LOVEL, Peggy. Desigualdade racial no Brasil contemporâneo. Belo Horizonte: UFMG/CEDEPLAR, 1991. p 121-159.

Feminização da pobreza: um cenário neoliberal. In: GALEAZZI, I. (Org). Mulher e trabalho. Porto Alegre: 2001. p.89-96.

CHANT, Sylvia. Dangerous equations? How femaleheaded households became the poorest of poor: causes, consequences and cautions. IDS Bulletin: Institute of Development Studies, v. 35, n.4, p.19-25., oct., 2004.

CIOFFI, Sylvia. Famílias metropolitanas: arranjos familiares e condições de vida. In: ENCONTRO NACIONAL DE ESTUDOS POPULACIONAIS DA ABEP, 11, Caxambu, 1998, Anais..., Caxambu: ABEP, 1998, p.1041-1070. Disponível em: www.abep.nepo.unicamp.br/ docs/anais/PDF/ 1998/a165.pdf. Acesso: 9 out., 2007.

CORRÊA, Marisa. Repensando a família patriarcal brasileira (notas para o estudo das formas de organização familiar no Brasil). In: ALMEIDA, Maria Suely Kofes. Colcha de retalhos: estudos sobre a família no Brasil. São Paulo: Brasiliense, 1982. p.13-38.

COSTA, Dora Isabel Paiva. As mulheres chefes de domicílios e a formação de famílias monoparentais em Campinas, São Paulo - 1829. In: ENCONTRO NACIONAL DE ESTUDOS POPULACIONAIS DA ABEP, 11, Caxambu, 1998,. Anais... Caxambu: ABEP, 1998. p.1145-1180

DIAS, Maria Odila Leite da Silva. Quotidiano e poder em São Paulo no século XIX. São Paulo: Ed. Brasiliense, 1984.

FARAH, Marta F. S. Gênero e políticas públicas. Estudos Feministas, Florianópolis, Centro de Filosofia e Ciências Humanas, Centro de Comunicação e Expressão/UFSC., v.2, n.1, p.47-71, 2004.

FIGUEIREDO, Mariza. O papel sócio-econômico das mulheres chefes de família numa comunidade pesqueira do litoral norte da Bahia. Cadernos de Debate: a estrutura familiar na opressão feminina, São Paulo, Brasiliense, n.6, p.35-78, 1980.

FONSECA, Cláudia. Mulher chefe-de-família? Revista de Ciências Sociais, Porto Alegre, v.1, n.2, p. 261-268, 1987.

GOLDANI, Ana Maria. Desigualdade racial nas trajetórias de vida familiar das mulheres brasileiras. In: LOVEL, Peggy. 
Desigualdade racial no Brasil contemporâneo. Belo Horizonte: UFMG/CEDEPLAR, 1991. p.195-238.

Retratos da família em tempos de crise. Estudo Feministas, Rio de Janeiro, CIEC/ECO/UFRJ, n.especial, p.303-335, 1994.

Famílias e gêneros: uma proposta para avalia (des)igualdades. In: ENCONTRO NACIONAL DE ESTU DOS POPULACIONAIS, 12, Caxambu, 2000, Anais.. Caxambu, MG 2000, 20p. Disponível em: www.abep.nepo.unicamp.br/docs/anais/pdf/ 2000/Todos/ gent2_1.pdf. Acesso em: 15 set., 2006.

. Família, gênero e políticas: famílias brasileiras nos $\overline{\operatorname{anos} 9} 0$ e seus desafios como fator de proteção. Revista Brasileira de Estudos de População, São Paulo, v.19, n.1, p.29-48, jan./jun., 2002. Disponível em: www.abep.nepo.Unicamp.br/docs/rev_inf/vol_19_n1 2002/vol19_n1_2002_2artigo_29_48.pdf. Acesso em: 15 set., 2006 .

GONZÁLEZ DE LA ROCHA, Mercedes. Gênero e pobreza urbana: observacões para uma discussão. In : SEMINÁRIO SOBRE POBREZA URBANA. Rio de Janeiro: ALOP and The World Bank, May 14-16, 1998, 11p. Disponíve em: http://wbln0018.worldbank.org/LAC/ LACInfoClient.nsf/d29684951174975c85256735007fef12/ 31e7e4f5a6cc34b285256804004b90fe?OpenDocumen Acesso em: 20 ago., 2006.

A manera de introducción: cambio social, transformación de la família y divergencias del modelo tradicional. In: (Coord). Divergencias del modelo tradicional: hogares de jefatura feminina en América Latina. México: CIESAS, 1999. p.19-36.

HITA, M. G. As casas das mães sem terreiro: etnografia de modelo familiar matriarcal em bairro popular negro da cidade de Salvador. 2004. Tese (Doutorado) - IFCH UNICAMP, SP, 2004.

IBGE. Síntese dos indicadores sociais: uma análise da condições de vida da população brasileira. Rio de Janeiro, 2007, 252p. (Série estudos e pesquisas, n.21)

LAVINAS, Lena. As mulheres no universo da pobreza: caso brasileiro. Estudos Feministas, Rio de Janeiro, v.4, n.2, p.464-479, 1996.

MACHADO NETO, Zahidé. Mulher: dimensão de sobrevivência / dimensão de existência. 1979. 111f. Tese (Doutorado) - Faculdade de Filosofia, Letras e Ciências Humanas da USP, São Paulo, 1979.

MACÊDO, Márcia S. Tecendo os fios e segurando as pontas: trajetórias e experiências entre mulheres chefes de família em Salvador. 1999. 185f. Dissertação (Mestrado) - Programa de Pós-Graduação em Ciências Sociais/Faculdade de Filosofia e Ciências Humanas, Universidade Federal da Bahia.

MARTELETO, Letícia J. Quando parentes tomam conta das criancas: arranjos de child care em domicílios intactos e chefiados por mulheres. In: ENCONTRO NACIONAL $\therefore$ DE ESTUDOS POPULACIONAIS DA ABEP, 11. Caxambu, 1998. Anais..., Caxambu: 1998. p.2633-2661.

MATTOSO, Kátia de Queirós. Família e sociedade na Bahia do século XIX. São Paulo: CNPq/Currupio, 1988.

MEDEIROS, M. OSORIO, R. Mudancas na composição dos arranjos domiciliares no Brasil - 1978 a 1998. Fórum as Transformações Recentes da(s) Família(s) Brasileira(s) In: REUNIÃO DA ASSOCIAÇÂO BRASILEIRA DE AN TROPOLOGIA, Brasília, 2000.

MENDES, Mary Alves. Mulheres chefes de família: a complexidade e ambigüidade da questão. In: PRÉ-EVENTO MULHERES CHEFES DE FAMÍLIA: crescimento, diversidade e políticas. Ouro Preto: CNPD, FNUAP e ABEP 2002, 13p. Disponível em: www.abep.nepo.unicamp.br/ docs/anais/pdf/2002/GT_Gen_ST38_Mendes_texto.pdf
Mulheres chefes de domicílios em camadas pobres: trajetória familiar, trabalho e relações de gênero. In ENCONTRO NACIONAL DE ESTUDOS POPULACIONAIS, 14, Caxambu, 2004. Anais..., Caxambu, MG, 2004, p.1145-1180. Disponível em: www.abep.nepo. unicamp.br/site_eventos_abep/PDF/ ABEP2004_787.pdf. Acesso em: 16 ${ }^{-}$set., $200 \overline{6}$.

MOGHADAM, V. The feminisation of poverty: notes on concept and trend. Womens's Studies Ocasional Paper 2 , Illinois, State University, 1997.

MONTALI, Lilia. Provedoras e co-provedoras: mulheres-cônjuge e mulheres-chefe de família sob a precarização do trabalho e o desemprego. In: ENCONTRO NACIONAL DE ESTUDOS POPULACIONAIS, 15, Caxambu, MG, ABEP, 2006 27p. Anais..., Disponível em: www.abep.nepo.unicamp.br/ encontro2006/docspdf/ABEP2006_251.pdf. Acesso em: 20 set., 2006

NEUPERT, R.F., CALHEIROS, S.M.G., \& TURCHI, L.M. Os arranjos domiciliares das famúlias matrifocais. In: ENCONTRO NACIONAL DE ESTUDOS POPULACIONAIS, 6 Olinda, PE, 1998. Anais..., Olinda, PE: ABEP, 1988.

NEVES, Delma Pessanha. Nesse terreiro galo não canta. Estudo do caráter matrifocal de unidades familiares de baixa renda. Anuário Antropológico, Fortaleza, UFCE/Tempo Brasileiro, n.83, p.199-221, 1985.

NOVELLINO. Maria S. F. Feminização da pobreza no Rio de Janeiro, Brasil (1992-1999). In: ENCONTRO DA ASSOCIAÇÃO BRASILEIRA DE ESTUDOS POPULACIONAIS, 13 Ouro Preto, 2002, 22p. Disponível em: www.abep.nepo.unicamp.br/docs/anais/pdf/2002/ GT_Gen_ST38_Novellino_texto.pdf. Acesso em: 20 set., $20 \overline{0}$.

Os estudos sobre feminização da pobreza e políticas públicas para mulheres In: ENCONTRO NACIONAL DE ESTUDOS POPULACIONAIS, 14, Caxambu, MG, 2004, 12p. Disponível em: www.abep.nepo.unicamp.br/site eventos_abep /PDF /ABEP2004_51.pdf. Acesso em $2 \overline{0}$ set., $20 \overline{06}$.

OLIVEIRA. Guacira C. Mulheres chefes de família - estratégias de ação. In: PRE-EVENTO MULHERES CHEFES DE FAMÍLIA: crescimento, diversidade e políticas. Ouro Preto: CNPD, FNUAP E ABEP, 2002, 10p. Disponível em: www.abep.nepo.unicamp.br/ XIIIencontro/Guacira.pdf Acesso em: 15 set., 2006.

OLIVEIRA, Maria Coleta F. A. Condição feminina e alternativas de organização doméstica: as mulheres sem companheiro em São Paulo. In: ENCONTRO NACIONAL DE ESTUDOS POPULACIONAIS DA ABEP, 8, Caxambu, MG, 1992. Anais..., Brasília: ABEP, 1992, v.2,.p.57-178.

OLIVEIRA, Orlandina; GARCÍA, Brígida. Mujeres jefas de hogar y su dinâmica familiar. In: CONGRESSO DA ASSOCIAÇÃO LATINO AMERICANA DE POPULAÇÃO ALAP, 1, Caxambu-MG, set. 2004, 18p.

OLIVEIRA, Sonia; SABOIA, Ana Lucia; SOARES, Bárbara. Dimensões preliminares da responsabilidade feminina pelos domicílios: um estudo do fenômeno a partir dos censos demográficos 1991 e 2000. Rio de Janeiro: IBGE, Departamento de População e Indicadores sociais, 2002. 55p. (Série textos para discussão, n.7).

OLIVEIRA, Zuleica L. C. Política de informação na área de gênero. In: ENCONTRO NACIONAL DE CIÊNCIA DA INFORMACÃO, 5. Salvador: Instituto de Ciência da Informação/ Programa de Pós-Graduação/UFBA, jun.2004, 14p. Disponível em: www.cinform.ufba.br/v_anais/artigos/zuleica cavalcante. html Acesso em: 23 dēz., 2005

. A provisão da família e a pobreza: o caso de Belo Horizonte. In: SEMINÁRIO AS FAMIILIAS E AS POLÍTICAS PÚBLICAS NO BRASIL. Belo Horizonte, 2005a, 15p. Disponível em: www.abep.nepo.unicamp.br/docs/anais/outros/ FamPolPublicas/ZuleicaOliveira.pdf. Ácesso em: 28. ago., 2007. 
. A provisão da família: redefinição ou manutenção do papeis? In: ARAÚJO, Clara; SCALON, Celi. Gênero, família e trabalho no Brasil. Rio de Janeiro: FGV/ FAPERJ, 2005b. p.123-147.

PINNELLI, Antonella. Gênero e família nos países desenvolvidos. Demographicas, Campinas, SP, ABEP, n. 2, p.5598. 2004.

PIOLA, Sérgio F; OSÓRIO, Rafael G. Chefia feminina e saúde, um enfoque preliminar. In: PRÉ-EVENTO MULHERES CHEFES DE FAMÍLIA: crescimento, diversidade e políticas. Ouro Preto: CNPD, FNUAP, ABEP, 2002, 13p. Disponível em: www.abep.nepo. unicamp.br/ XIIIencontro/osorio_\&_piola.pdf. Acesso em: 28 set., 2006.

SAFA, Helen I. De mantenidas a proveedoras: mujeres e industrialización en el Caribe. San Juan: Editorial de la Universidad de Puerto Rico, 1998.

Prólogo. In: GONZÁLEZ DE LA ROCHA (Coord). Divergencias del modelo tradicional: hogares de jefatura feminina en América Latina. México: CIESAS, 1999. p.917.

SAFFIOTI, Heleieth B. No caminho de um novo paradigma. Araraquara, SP: Centro de Referência da Mulher Profa. H. Saffioti/Prefeitura Municipal de Araraquara. 2002, 14p. Disponível em: www.araraquara.sp.gov.br/ secretaria governo/ pagina_indice.asp? iditem $=196$. Acesso em : 12 ago., 2006.

SALEM, Tânia. Mulheres faveladas: "com a venda nos olhos". Perspectivas Antropológicas da Mulher. São Paulo, Zahar Editores, n. 4, p.49-99, 1981.

SAMARA, Eni de Mesquita. Mulheres chefes de famílias no Brasil: séculos XIX e XX. In: PRÉ-EVENTO MULHERES CHEFES DE FAMÍLIA: crescimento, diversidade $e$ políticas. Ouro Preto: CNPD, FNUAP E ABEP, 2002, 20p. Disponível em: www.abep.nepo.unicamp.br/XIIIencontro/ Eni Samara Apresentaçao Pre Congresso.pdf . Acesso em: 18 set., $\overline{2} 006$.

SANTOS, Martha Maria Rocha. Arranjos familiares e desigualdades raciais entre trabalhadores em Salvador e Região Metropolitana - Bahia. 1996, Dissertacão (Mestrado em Sociologia) - Faculdade de Filosofia e Ciếncias Humanas, UFBA, 1996.
SCAVONE Lucila. Maternidade: transformações na família e nas relações de gênero. Revista Interfaces, Botucatu,SP, v.5, n.8, p.47-60, 2001. Disponível em: www.interface. org.br/revista8/ensaio3.pdf. Acesso em 12 set., 2006.

SCOTT, Russell Parry. Homens e mulheres sem cônjuges: tendências recentes em Pernambuco. In: ENCONTRO NACIONAL DE ESTUDOS POPULACIONAIS DA ABEP 7, Caxambu,MG, 1990a. Anais..., Caxambu: ABEP, 1990a. v. 1, p. $275-294$.

O homem na matrifocalidade: gênero, percepção e experiências do domínio doméstico. Cadernos de Pesquisa, São Paulo, n.73, p.38-47, 1990b.

Mulheres chefes de família: estudos apresentados em associacões acadêmicas nacionais. In: PRE-EVENTO MULHERES CHEFES DE FAMÍLIA: crescimento, diversidade e políticas. Ouro Preto, 2002a. CNPD, FNUAP, ABEP, 30p. Disponível em: www.abep.nepo.unicamp.br/ XIII encontro/Scott intromulherchefe pdf. Acesso em: 18 set. 2006.

Mulheres chefes de família: abordagens e temas para as políticas públicas. In: PRÉ-EVENTO MULHERES CHEFES DE FAMÍLIA: crescimento, diversidade e políticas. Ouro Preto, MG: CNPD, FNUAP e ABEP, 2002b, 11p. Disponível em: www.abep.nepo.unicamp.br/ XIIIencontro/Scott_intro_mulher_chefe.pdf Acesso em: 18 set., 2006

SOUZA, Marcelo. A importância de se conhecer melhor as famílias para a elaboração de políticas sociais na América Latina. Texto de Discussão, Rio de Janeiro, IPEA, n. 699. 2000. Disponível em: www.ipea.gov.br/pub/td/2000/ td_0699.pdf. Acesso em: 12 ago., 2007.

VITALE, Maria Amália F. Famílias monoparentais: indagações. Serviço Social e Sociedade, [S.1.], n.71, Ed. especial, p.45-62, set., 2002.

WOORTMANN, Klaas. A família das mulheres. Rio de Janeiro: Tempo Brasileiro, 1987.

; WOORTMANN, Ellen F. Monoparentalidade e chefia feminina: conceitos, contextos e circunstâncias. In: PRE - EVENTO MULHERES CHEFES DE FAMÍLIA: crescimento diversidade e políticas. Ouro Preto: ABEP 2002, 99p. Disponível em: www.abep. nepo.unicamp.br XIII encontro/woortmann.pdf. Acesso em 18 set., 2006. 


\section{WOMEN HEADS OF FAMILY AND THE GENDER PERSPECTIVE: the trajectory of a theme and the criticism on the feminization of poverty}

\author{
Márcia dos Santos Macedo
}

This essay presents a brief review of the trajectory of the studies on women heads of the family and it accomplishes a critical reflection about the direct relationship established between the growth of the phenomenon of the feminine leadership of the family and the polemic debate about the so-called feminization of poverty. It intends to point to the need of questioning an artificial homogeneity built around women heading their domestic-family nuclei, presented by most of the studies, and that insists on reinforcing an uniform profile of those women - seen, predominantly, as the poorest among the poor - and it signals, finally, to the open possibilities of gender studies, particularly of those that join a feminist and relational epistemology, for a new look on that polissemic and multifaceted object.

KEYwORDS: women heads of family, feminization of the poverty, gender relationships.

\section{LES FEMMES CHEFS DE FAMILLE ET LA PERSPECTIVE DE GENRE: la trajectoire d'un thème et la critique de la féminisation de la pauvreté}

\author{
Márcia dos Santos Macedo
}

Cet essai présente un bref rappel de la trajectoire des études concernant les femmes chefs de famille et fait une réflexion critique sur la relation directe qui existe entre le phénomène croissant des femmes chefs de famille et la controverse sur le débat de la dite féminisation de la pauvreté. On essaie de montrer le besoin de remettre en question l'homogénéité artificielle construite à propos des femmes qui assument le rôle de chef autant au niveau de la maison que de la famille, présentée dans la majorité des recherches et qui insiste sur le fait de vouloir renforcer un profil uniforme de ces femmes. Celles-ci sont vues surtout comme étant les plus pauvres parmi les pauvres. On voit enfin les possibilités offertes par les études de genre, en particulier par celles qui adhérent à une épistémologie féministe et relationnelle, de porter un nouveau regard sur cet objet polysémique et aux multiples facettes.

Mots-CLÉs: femmes chefs de famille, féminisation de la pauvreté, relations de genre. 